Artigo / Article

\title{
New drugs in the treatment of chronic myeloid leukaemia
}

\section{Novas drogas no tratamento da leucemia mielóide crônica}

\author{
Daniela Cilloni \\ Antonia Rotolo \\ Paolo Nicoli \\ Marco Bosa \\ Giuseppe Saglio
}

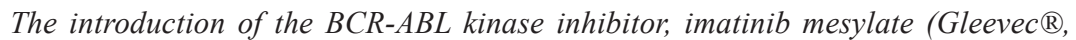
Novartis) led to significant changes in the treatment of chronic myeloid leukaemia (CML) patients. However, despite the impressive percentage of responding patients, some CML cases, particularly those in advanced phases of the disease, show primary resistance or relapse after the initial response. The second-generation $B C R-A B L$ inhibitors nilotinib (Tasigna ${ }^{\circledR}$, Novartis) and dasatinib (Sprycel ${ }^{\circledR}$, Bristol-Myers Squibb) have shown significant activity in clinical trials in patients who failed imatinib therapy, but these agents are still incapable of inhibiting the T315I mutant of Bcr-Abl and present partial activity in advanced phases of CML. The acquired biological notions of the mechanisms of tyrosine kinase inhibitor (TKI) resistance has led to the development of new compounds, some of which have shown encouraging preliminary results in clinical trials, even against T315I mutants. In this paper we discuss the new emerging therapies which may overcome TKI resistance in CML patients. Rev. bras. hematol. hemoter. 2008; 30(Supl. 2):24-29.
\end{abstract}

Key words: Chronic myeloid leukaemia; BCR-ABL kinase inhibitors; TKI resistance.
The first BCR-ABL inhibitor to come into the clinical practice, imatinib mesylate, is now the first-choice of treatment for all newly diagnosed CML patients. This drug was tested in phase I and II clinical trials and soon moved to a phase III randomised trial (International Randomised Study of Interferon versus ST1571 [IRIS]) in which the drug was compared with interferon alfa plus cytosine arabinoside (IFN $\alpha$ plus ARA-C). ${ }^{1}$ The treatment provides an impressive rate of complete haematological responses (CHR) and complete cytogenetic remissions ( $\mathrm{CCgR}$ ), assessed at $95 \%$ and $94 \%$, respectively for imatinib, compared with $55 \%$ and $8.5 \%$ for IFN $\alpha$ - ARA-C. Progression free survival at 18 months was $96.7 \%$ for imatinib compared with $91.5 \%$ for IFN $\alpha$ ARA-C . The data coming from the IRIS trial have been recently updated ${ }^{2}$ and show that the cumulative incidences of CHR and $\mathrm{CCgR}$ at 5 years are $98 \%$ and $87 \%$, respectively, for imatinib. For those patients achieving a CCgR at 18 months or for patients obtaining a major molecular response (MMR) (three-log reduction in leukemic cells), the 5-year progressionfree survival is $97 \%$ and $99 \%$, respectively. Despite the impressive percentage of responding patients, some CML cases, particularly in the more advanced phases of the disease, show primary resistance or relapse after an initial response. ${ }^{1,2}$ The most common mechanisms of resistance include: (i) BCRABL kinase domain mutations; (ii) BCR-ABL overexpression; (iii) clonal evolution with activation of additional transformation pathways. ${ }^{3,4}$

One of the most studied mechanism of resistance to imatinib therapy is the development of point mutations within the kinase domain of $B C R-A B L$. The frequency of $B C R-A B L$ mutations in imatinib resistant patients ranges from $40 \%$ $90 \%$ depending on the CML phase and on the methodology for the detection. ${ }^{5-6}$

Depending on the region where they are located, mutations can actually act by interrupting critical contact points between the drug and $\mathrm{BCR} / \mathrm{ABL}$ protein or by inducing a conformational change to which imatinib is unable to bind. At present, approximately 90 different $\mathrm{BCR} / \mathrm{ABL}$ mutations have been identified in patients with Imatinibresistant CML through random mutagenesis in vitro. Many

Department of Clinical and Biological Sciences, University of Turin - Italy

Ospedale San Luigi Orbassano - Medicina Interna - 10043

Correspondence: Daniela Cilloni

Department of Clinical and Biological Sciences, University of Turin - Italy

Ospedale San Luigi Orbassano - Medicina Interna - 10043

E-mail:daniela.cilloni@unito.it 
of these are relatively rare, whereas the most common, which account for $60 \%-70 \%$ of all the mutations, affect residues Gly250, Tyr253, Glu255, Thr315, Met351 and Phe359.' Mutations also differ from each other for the kind of resistance they can determine: some mutant clones are completely resistant (Y253F/H, E255K, T315I), others only partially (M244V, F317L, Met351T), depending on whether the bound with the drug following the amino acid substitutions is prevented or only hindered. In this latter case, the sensibility can be restored by simply increasing the imatinib dose. The mutations with a greater level of resistance fall inside the ATP binding site of the KD domain, an highly conserved region responsible for phosphate binding and known as phosphate-binding loop (P-loop) (a.a. 248-256, motif LGGGQYGEV). Initially these mutations have been also associated with an especially poor prognosis ${ }^{6,8}$ but this still remains, at the moment, a matter of debate.

Several approaches to overcome resistance have been proposed including the development of more powerful tyrosine kinase inhibitors (TKIs) which are under investigation in clinical or pre-clinical studies on patients with imatinib-resistant or intolerant CML, at any stage of the disease. Classes of these new inhibitors include selective ABL inhibitors (nilotinib), inhibitors of both ABL and Srcfamily kinases dasatinib, bosutinib, INNO-404, AZD0530), Aurora Kinase inhibitors (MK-0457, PHA-739358), and non-ATP competitive inhibitors of BCR/ABL (ON012380) (Table 1). All these drugs have proved effective in preclinical studies against the mutant enzymes, and significal clinical responses in clinical trials have been reported for many of these. ${ }^{9,10}$

Dasatinib (Sprycel ${ }^{\circledR}$, Bristol-Myers Squibb) has recently been approved by the FDA and by EMEA for the treatment of adults with CP, AP, or myeloid or lymphoid BP $\mathrm{CML}$ with resistance or intolerance to prior therapy including

Table 1. New tyrosine kinase inhibitors (TKI

\begin{tabular}{lccc}
\hline \multicolumn{1}{c}{ Compound } & Company & Targets & Clinical phase \\
\hline $\begin{array}{l}\text { Dasatinib } \\
\text { (BMS-354825) }\end{array}$ & Bristol-Meyers & $\begin{array}{c}\text { ABL, KIT, PDGFR, } \\
\text { EPHB4,SRC and } \\
\text { SRC family kinases }\end{array}$ & Approved \\
Nilotinib (AMN 107) & Novartis & ABL, KIT, PDGFR, EPHB4 & II \\
Bosutinib (SKI-606) & Wyeth & ABL, FGR, LYN, SRC & II \\
AZD0530 & Astra Zeneca & ABL, SRC & II(solid tumors) \\
MK-0457(VX-680) & Merck & ABL (T315I included), Aurora & II \\
kHA-739358 & Nerviano & Aurora A,B and C & I \\
INNO-406 (NS-187) & Innovive & ABL, LYN, PDGFR,KIT & I \\
AP23464 & Ariad & ABL, SRC & Pre-clinical \\
CGP76030 & Pfizer & SRC & Pre-clinical \\
\hline
\end{tabular}

imatinib. Dasatinib is also indicated for the treatment of adults with resistant $\mathrm{Ph}+$ positive acute lymphoblastic leukaemia.

Dasatinib is a multikinase inhibitor with potent activity against BCR-ABL kinase (IC50 $<1 \mathrm{nM}$ ) and Src family kinases (IC50 of 0.2-1.1 nM ). Dasatinib inhibits all imatinib resistant kinase domain mutations tested, with the exception of T315I. ${ }^{11}$

This compound is able to bind ABL with greater affinity as compared to imatinib. This is, at least in part, due to the ability of recognizing multiple ABL configurations. This feature provides a potential clinical advantage over imatinib and nilotinib. ${ }^{12}$ As a result, the number of $B C R-A B L$ mutants that confer resistance to dasatinib is limited almost exclusively to those directly affecting the contact sites. ${ }^{13}$

A potential limitation of these new drugs is the increased degree of toxicity which may be caused by an increased potency but it may be also related to their inhibitory activity against a broader range of protein kinases. For instance, dasatinib acts potently on many members of the Scr kinase family and also on KIT, PDGFR and ephrin receptor (EPHA2) tyrosine kinases, which are directly implicated in many biological processes. These effects may provide the physiological explanation for some of the toxicities observed such as pleural effusion and myelosuppression. However the inhibition of Src kinases may also be crucial and of clinical benefit for the cure of imatinib-resistant CML and $\mathrm{Ph}$-positive B- ALL. In these settings the pathogenetic role of many members of the Src family has been demonstrated, such as the overexpression of Lyn. ${ }^{14,15}$ The Src kinases family comprises nine non-receptor tyrosine kinases (SRC, FYN, YES, BLK, YRK, FGR, HCK, LCK, LYN). 16 Some Src members are ubiquitously expressed, whereas others display tissuespecific expression patterns. ${ }^{16}$

Published data support the evidence that Src kinases are involved in the proliferation of $B C R-A B L$-expressing cell lines. ${ }^{17}$ The activation of many Src kinases such as LYN and HCK seems to be dependant from the interaction with $\mathrm{BCR}-\mathrm{ABL}$, but not from its kinase activity, as demonstrated by the presence of multiple interactions between the BCR-ABL domains and HCK and LYN, finally resulting into their activation. ${ }^{18,19}$ This activation is not influenced by the effective block of BCR-ABL kinase activity.

Importantly, the kinases LCK and FYN are linked with the coreceptors CD4 and CD8 and have a crucial role in mediating T-cell-receptor signal transduction in clonal lymphocytes. ${ }^{20}$

Finally, the role of Src kinases in the pathogenesis of chronic phase CML remains to be fully understood. 
Transduction of $B C R-A B L$ into bone marrow from mice lacking HCK, LYN and FGR can efficiently induce a CML-like myeloproliferative disorder. ${ }^{21}$ In addition, mice with CMLlike disease responded to imatinib but not to the treatment with selective inhibitors of Src kinases. However, HCK, LYN and FGR are required for $B C R-A B L$-induced B ALL.

Dasatinib may target an earlier progenitor population than imatinib in CML patient isolates, although the most primitive quiescent cells may be inherently resistant to both drugs. ${ }^{22}$ Results from the START programs demonstrated that treatment with dasatinib at a dose of $70 \mathrm{mg}$ twice daily resulted in hematologic, cytogenetic and molecular responses across all phases of CML in both imatinib-intolerant and imatinibresistant patients, including those harbouring Bcr-Abl mutations with the exception of the T315I. ${ }^{9}$

Nilotinib (Tasigna ${ }^{\circledR}$, Novartis) is a phenylaminopyrimidine derivative developed by the reconciliation of the crystal structures of imatinib ${ }^{23}$ with increased affinity for the inactive conformation of wild-type BCR-ABL by 20 -fold to 30 -fold, while similar activity against KIT, PDGFR is maintained. Results from the pivotal phase II studies of nilotinib for patients with CML after failure or intolerance to imatinib therapy indicate that nilotinib has a favorable toxicity profile and is highly efficacious in this setting. ${ }^{10}$

Similarly to imatinib, nilotinib binds Bcr-Abl only in its inactive conformation. ${ }^{24}$ Nilotinib inhibits almost all the BcrAbl mutants, but, like dasatinib, it is unable to inhibit T315I mutant. Nilotinib at the dose of $400 \mathrm{mg}$ twice a day has been examined in patients with CML resistant or intolerant to imatinib in all phases of disease where it proves able to induce hematologic, cytogenetic and molecular responses. Nilotinib treatment is well tolerated and associated with a very favorable toxic profile which includes myelosuppression, skin rashes, nausea and peripheral oedema represented the most frequent side effects. ${ }^{24}$

Many other Bcr-Abl inhibitors are currently in early clinical development and bosutinib (SKI-606) and INNO-406 (NS-187) have reached Phase I-II trials..$^{25,26}$

Bosutinib, (SKI-606, Whyet) is an orally available 4 anilino 3-quinolinecarbonitrile derivative. ${ }^{25}$ It is classified as a dual Src/Abl kinase inhibitor which inhibits Bcr-Abl with a 200 -fold increased potency as compared to imatinib and it is active against imatinib-resistant $\mathrm{Bcr}-\mathrm{Abl}$ mutant proteins and against three different $B C R$ - $A B L$-positive cell lines, including LAMA84R, in which resistance is caused by $B C R-A B L$ gene amplification, and K562R and KCL22R in which the mechanism of resistance has not yet been defined. ${ }^{27}$

Unlike imatinib and dasatinib, SKI-606 exhibits no significant inhibition of c-kit or PDGFR thus resulting in a safer toxicity profile in vivo. ${ }^{27}$ This differential selectivity may result in clinical benefit by decreasing some adverse events, in particular those due to fluid retention. In a phase I study, patients in chronic phase with imatinib relapsed or refractory disease were shown to achieve a consistent percentage of complete hematologic and cytogenetic responses with encouraging evidence of clinical activity in imatinib-resistant patients with BCR-ABL mutations. ${ }^{27,28}$ Bosutinib was given as a single dose at $400 \mathrm{mg}, 500 \mathrm{mg}$, or $600 \mathrm{mg}$ daily. Side effects were minimal with the most frequent being mild to moderate diarrhoea (87\%), nausea (33\%) and vomiting $(20 \%) .{ }^{28}$ In contrast to dasatinib, no pleural effusion or pulmonary oedema was observed with bosutinib. The doselimiting toxicity of bosutinib occurred at $600 \mathrm{mg}$ daily. A dose of $500 \mathrm{mg}$ daily was selected as the dose for the Phase II study, which is currently recruiting patients in all phases of CML and $B C R-A B L$-positive B ALL. ${ }^{28}$

The superior spectrum of activity of bosutinib with respect to imatinib may be attributed to its ability to bind both inactive and intermediate conformations of BCR-ABL. ${ }^{28}$ Importantly, bosutinib is significantly more potent than imatinib in inhibiting BCR-ABL tyrosine kinase in both primitive and committed CD34+CD38- progenitors from untreated CML patients.

On the basis of these results, bosutinib is currently being tested in patients with CML who have become resistant to imatinib or to the second-generation TKIs nilotinib and dasatinib.

Quite recently a novel BCR-ABL/LYN dual inhibitor INNO-406 (NS-187) which apparently shows unique profile to overcome imatinib resistance has been introduced in clinical studies. INNO-406 is a is a 3 -substituted benzamide derivative, is a dual-specificity ABL and LYN kinase inhibitor that is 25-55-times more potent than imatinib against ABL. ${ }^{29}$ In addition, INNO-406 inhibited the in vitro growth of cells with different mutant forms of BCR-ABL oncoproteins, ${ }^{30}$ but not with T315I. ${ }^{29,30}$ INNO-406 inhibited kinases other than ABL including ABL-related gene $A R G$ and FYN, but not PDGFR $\alpha / \beta$, SRC, BLK or YES. Furthermore, INNO-406 potently inhibited LYN kinase (IC50 of $19 \mathrm{nM}$ ), which has been implicated in BCR-ABL independent resistance, ${ }^{13}$ without affecting the phosphorylation of Src, Blk or Yes, therefore presenting a further potential in imatinib-resistant CML ${ }^{26}$ In addition, the ability of NS-187 to specifically target the Bcr-Abl and Lyn kinases may result in a better side effect profile than agents that target multiple kinases such as Src/ Abl inhibitors. ${ }^{29}$

Approximately $6 \%$ of adult patients in lymphoid blast phase CML have evidence of central nervous system (CNS) involvement. The concentration of INNO-406 in CNS is about $10 \%$ of that detected in the plasma. ${ }^{30}$ Due to the low concentrations reached by nilotinib or dasatinib in the CNS at the dose administered in clinical practice, INNO 406 represents a promising alternative for the treatment of CNS $B C R-A B L 1$-positive leukaemia.

None of the described agents however are capable of inhibiting the T315I mutant of Bcr-Abl. MK-0457 (Merck Sharp and Dome, previously VX-680) is a small-molecule which inhibits the aurora kinases A, B, and C, and wild type and 
mutant BCR-ABL, including the T315I variant. ${ }^{31}$ The human Aurora kinases (AURKs), AURKA, AURKB and AURKC, are essential for proliferation and for the correct progression through the mitotic phase of the cell cycle..$^{32}$ Aurora kinase A and $\mathrm{B}$ are overexpressed or gene amplified in several human malignancies. In enzyme activity assays, MK 0457 inhibited wild-type ABL and the ABL T315I mutant isoform, with IC50 of $10 \mathrm{nM}$ and $30 \mathrm{nM}$, respectively. ${ }^{33}$ Furthermore, MK 0457 inhibited the viability of $\mathrm{Ba} / \mathrm{F} 3$ cells transformed by wildtype, Y253F or T315I mutants of BCR-ABL (IC50 300 nM). ${ }^{34}$ A relevant difference, when compared to imatinib, in terms of mechanism of action is that when penetrates deeply into the ABL kinase domain, MK 0457 anchors itself firmly at the hinge region and engages Asp381 at a much more superficial level within the kinase domain. ${ }^{31}$ This allows MK 0457 to overcome the potential steric constraints imposed by the mutant ABL T315I kinase. In a recent Phase I study, eleven patients with $B C R-A B L$ T315I-positive refractory CML have been treated with MK-0457. One patients obtained a major haematological response, four minor haematological responses and four cytogenetic responses.$^{35}$ Remarkably, no drug-related non-hematological toxicity was observed. Some patients showed an apparent myelosuppression, which is an expected mechanism-based side effect of Aurora kinase inhibition. MK-0457 was very well tolerated. ${ }^{36}$

MK-0457 is therefore the first T315I BCR-ABL inhibitor to show activity against this highly refractory, poor prognostic subpopulation of CML.

All TKIs currently used for the treatment of CML compete with ATP for the binding site of the BCR-ABL oncoprotein. An alternative strategy to target ABL kinase involves the development of small molecules targeting BCRABL motifs that are remote from the kinase domain. Such compounds may potentially be unaffected by mutations of the kinase domain that make $B C R$ - $A B L$-positive leukaemic cells resistant to imatinib.

GNF 2 was identified as a highly selective inhibitor of proliferation in $\mathrm{BCR}-\mathrm{ABL}$ positive cells which is active against most clinically relevant imatinib-resistant BCR-ABL mutants. GNF 2 is the first compound which inhibits BCR-ABL kinase by binding to the autoregulatory myristate binding cleft of BCR-ABL located at the $N$ terminus, spatially distant from the active site of ABL kinase, which results in stabilization of the protein in an inactive state. ${ }^{37}$ This mode of action probably contributes to the synergistic effect between GNF 2 and imatinib. GNF 2 does not compete with any ABL substrate, and inhibits the proliferation of $B C R-A B L$-expressing cells in a selective, non-ATP-competitive manner with an IC50 of 138 $\mathrm{nM}$, but proved inactive against the catalytic domain of ABL kinase ${ }^{38}$ The selectivity of GNF 2 was further supported by its lack of activity against other kinases such as FLT3, KIT, PDGFR, LCK and SRC.

GNF 2 is the leading compound of a new class of putative allosteric ABL kinase inhibitors. Although the mechanism of action of GNF 2 is not yet fully characterized, its selectivity for BCR-ABL suggests that this agent may not present off-target effects and significant toxicity. Finally, LBH589 (Novartis) is a novel histone deacetylase inhibitor that inhibits proliferation and induces apoptosis in tumor cell lines, including cell lines harbouring the BCR-ABL mutant with T315I. LBH589 induces cell death through an increase in the mitochondrial outer membrane permeability and favous apoptosome formation by inducing cytochrome $\mathrm{c}$ release. In addition, LBH589 stimulates a caspase-independent pathway through the release of AIF from the mitochondria, downregulating Bcl-2 and particularly Bcl-X. All these data indicates that LBH589 could be a useful drug for the treatment of resistant CML patients including those with the T315I mutations. ${ }^{39}$

In summary, several novel tyrosine kinase inhibitors that have been developed to override imatinib resistance mechanisms such as overexpression of Bcr-Abl and point mutations within the Abl kinase domain, are currently competing. Inhibitors of Abl tyrosine kinase can be divided into two main groups, namely, ATP-competitive and ATP noncompetitive inhibitors. In addition, ATP competitive inhibitors can be subdivided into two subclasses: the Src/Abl inhibitors, and imatinib-like compounds. Dasatinib, SKI-606 are classified as Src/Abl inhibitors while nilotinib and NS-187 (INNO-406) belong to the latter subclass of inhibitors. Among these agents, clinical studies on dasatinib and AMN107 had started earlier than the others and favorable results are accumulating. Clinical studies of other compounds including SKI606 and INNO-406 are currently ongoing. Because of their strong affinity, most ATP competitive inhibitors may be effective against imatinib-resistant patients, including those harbouring mutations, but are ineffective against the T315I mutation. To address this problem, ATP non-competitive inhibitors such as Aurora kinase inhibitor MK-0457 and LBH589 have been developed. For the improvement of CML and $\mathrm{Ph}+\mathrm{ALL}$ treatment, maybe a combination therapy with novel ATP-competitive inhibitors and these new non-ATPcompetitive agents will be taken into consideration. ${ }^{40}$

\section{Resumo}

A introdução do inibidor de tirosino quinase BCR-ABL mesilato de imatinibe (Glivec ${ }^{\circledR}$, Novartis) levou a significantes mudanças no tratamento da LMC. Entretanto, a despeito de impressionante porcentagem de pacientes que respondem, alguns casos de LMC, particularmente em fases avançadas da doença mostram resistência primaria ou recidivas após terapêtica inicial. Inibidores de tirosino quinases de segunda geração como o nilotinibe (Tasigna ${ }^{\circledR}$, Novartis)

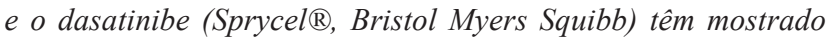
significante atividade nos estudos clínicos em paciente onde o imatinibe falhou. Porém, estes agentes não são capazes de inibir a mutação T315I do Bcr-Abl e apresentam atividade parcial em fases avançadas da LMC. As noções biológicas adquiridas sobre os 
mecanismos de resistência aos inibidores de TK levaram ao desenvolvimento de novos compostos alguns dos quais têm resultados preliminares encorajadores incluindo a mutação T315I. Neste trabalho nós discutimos os novos agentes emergentes e qual o potencial poderão atingir para ultrapassar a resistência aos inibidores de TK em pacientes com LMC. Rev. bras. hematol. hemoter. 2008; 30(Supl. 2):24-29.

Palavras-chave: Leucemia mielóide crônica; inibidores da quinase $B C R-A B L$; resistência aos TKI.

\section{References}

1. O'Brien SG, Guilhot F, Larson R.A, Gathmann I, Baccarani M, Cervantes $\mathrm{F}$, et al. Imatinib compared with interferon and lowdose cytarabine for newly diagnosed chronic-phase chronic myeloid. Leukaemia. N Engl J Med. 2003;348(11):994-1004.

2. Druker BJ, Guilhot F, O'Brien SG, Gathmann I, Kantarjian H, Gattermann N, et al. Five-year follow-up of patients receiving imatinib for chronic myeloid leukaemia. N Engl J Med. 2006; 355(23):2408-17.

3 Kantarjian HM, Talpaz M, Giles F, O’Brien S, Cortes J. New insights into the pathophysiology of chronic myeloid leukemia and imatinib resistance. Ann Intern Med. 2006;145(12):913-23.

4. Hochhaus A, Erben P, Ernst T, Mueller MC. Resistance to targeted therapy in chronic myelogenous leukemia. Semin Hematol. 2007; 44(1 Suppl 1):S15-24.

5. Gorre ME, Mohammed M, Ellwood K, Hsu N, Paquette R, Rao $\mathrm{PN}$, et al. Clinical resistance to STI-571 cancer therapy caused by BCR-ABL gene mutation or amplification. Science. 2001;293 (5531):876-80.

6. Soverini S, Martinelli G, Rosti G, Bassi S, Amabile M, Poerio A, et al. ABL mutations in late chronic phase chronic myeloid leukemia patients with up-front cytogenetic resistance to imatinib are associated with a greater likelihood of progression to blast crisis and shorter survival: a study by the GIMEMA Working Party on Chronic Myeloid Leukemia. J Clin Oncol. 2005;23:4100-09.

7. Weisberg E, Manley PW, Cowan-Jacob SW, Hochhaus A, Griffin JD.Second generation inhibitors of BCR-ABL for the treatment of imatinib-resistant chronic myeloid leukaemia. Nature Reviews Cancer. 2007;7:345-56.

8. Branford S, Rudzki Z, Walsh S, Parkinson I, Grigg A, Szer J, et al. Detection of BCR-ABL mutations in patients with CML treated with imatinib is virtually always accompanied by clinical resistance, and mutations in the ATP phosphate-binding loop (P-loop) are associated with a poor prognosis. Blood. 2003;102:276-83.

9. Hochhaus A, Kantarjian H, Baccarani M, Lipton JH, Apperley JF, Druker BJ, et al. Dasatinib induces notable hematologic and cytogenetic responses in chronic-phase chronic myeloid leukemia after failure of imatinib therapy, Blood. 2007;109:2303-09.

10. Kantarjian HM, Giles F, Gattermann N, Bhalla K, Alimena G, Palandri F, et al. Nilotinib (formerly AMN107), a highly selective BCR-ABL tyrosine kinase inhibitor, is effective in patients with Philadelphia chromosome-positive chronic myelogenous leukemia in chronic phase following imatinib resistance and Intolerance, Blood. 2007;110:3540-6.

11. Lombardo LJ, Lee FY, Chen P, Norris D, Barrish JC, Behnia K, et al. Discovery of N (2 chloro 6 methyl phenyl) 2 (6 (4 (2hydroxyethyl) - piperazin 1 yl) 2 methylpyrimidin 4 ylamino) thiazole 5 carboxamide (BMS 354825), a dual Src/Abl kinase inhibitor with potent antitumor activity in preclinical assays. J Med Chem. 2004;47:6658-6661.
12. Shah NP, Tran C, Lee FY, Chen P, Norris D, Sawyers CL. Overriding imatinib resistance with a novel ABL kinase inhibitor. Science. 2004;305:399-401.

13. Burgess MR, Skaggs BJ, Shah NP, Lee F, Sawyers CL. Comparative analysis of two clinically active BCR-ABL kinase inhibitors reveals the role of conformation-specific binding in resistance. Proc. Natl Acad Sci USA. 2005;102:3395-3400.

14. Donato NJ, Wu JY, Stapley J, Gallick G, Lin H, Arlinghaus R, et al. BCR-ABL independence and LYN kinase overexpression in chronic myelogenous leukemia cells selected for resistance to STI571. Blood. 2003;101:690-8.

15. Li S. Src-family kinases in the development and therapy of Philadelphia chromosome-positive chronic myeloid leukemia and acute lymphoblastic leukemia. Leuk Lymphoma. 2008;49:19-26.

16. Ingley E. Src family kinases: regulation of their activities, levels and identification of new pathways. Biochim Biophys Acta. 2008; 1784:56-65.

17. Stanglmaier M, Warmuth M, Kleinlein I, Reis S, Hallek M. The interaction of the BCR-ABL tyrosine kinase with the Src kinase Hck is mediated by multiple binding domains. Leukemia. 2003; 17:283-9.

18. Klejman A, Schreiner SJ, Nieborowska-Skorska M, Slupianek A, Wilson M, Smithgall TE, et al. The Src family kinase Hck couples BCR/ABL to STAT5 activation in myeloid leukaemia cells. EMBO J. 2002;21:5766-74.

19. Warmuth M, Bergmann M, Priess A, Häuslmann K, Emmerich B, Hallek M. The Src family kinase Hck interacts with BCR-ABL by a kinase-independent mechanism and phosphorylates the Grb2binding site of Bcr. J Biol Chem. 1997;272:33260-70.

20. Kappes DJ. CD4 and CD8: hogging all the Lck. Immunity. 2007; 5:691-3.

21. Hu Y, Liu Y, Pelletier S, Buchdunger E, Warmuth M, Fabbro D, et al. Requirement of Src kinases Lyn, Hck and Fgr for BCR-ABL1 induced B lymphoblastic leukaemia but not chronic myeloid leukemia. Nature Genet. 2004;36:453-61.

22. Copland M, Hamilton A, Elrick LJ, Baird JW, Allan EK, Jordanides $\mathrm{N}$, et al. Dasatinib (BMS-354825) targets an earlier progenitor population than imatinib in primary CML but does not eliminate the quiescent fraction. Blood. 2006;107:4532-9.

23. Weisberg E, Manley PW, Breitenstein W, Brüggen J, Cowan-Jacob SW, Ray A, et al. Characterization of AMN107, a selective inhibitor of native and mutant BCR-ABL. Cancer Cell. 2005;7:29-141.

24. Kantarjian H, Giles F, Wunderle L, Bhalla K, OBrien S, Wassmann $\mathrm{B}$, et al. Nilotinib in imatinib-resistant CML and Philadelphia chromosome-positive ALL. N Engl J Med. 2006;354:2542-51.

25. Golas JM, Arndt K, Etienne C, Lucas J, Nardin D, Gibbons J, et al. SKI-606, a 4-anilino-3-quinolinecarbonitrile dual inhibitor of Src and $\mathrm{Abl}$ kinases, is a potent antiproliferative agent against chronic myelogenous leukemia cells in culture and causes regression of K562 xenografts in nude mice. Cancer Res. 2003;63:375-81.

26. Kimura S, Naito H, Segawa H, Kuroda J, Yuasa T, Sato K, et al. NS187 , a potent and selective dual Bcr-Abl/Lyn tyrosine kinase inhibitor, is a novel agent for imatinib-resistant leukemia. Blood. 2005;106:3948-54.

27. Puttini M, Coluccia AM, Boschelli F, Cleris L, Marchesi E, DonellaDeana et al. In vitro and in vivo activity of SKI 606, a novel Src$\mathrm{Abl}$ inhibitor, against imatinib resistant $\mathrm{BCR}-\mathrm{ABL}+$ neoplastic cells. Cancer Res. 2006;66:11314-22.

28. Cortes J, Kantarjian HM, Baccarani M, Brummendorf TH, Liu D, Ossenkoppele G, et al. A phase 1/2 study of SKI-606, a dual Inhibitor of Src and Abl kinases, in adult patients with Philadelphia chromosome positive $(\mathrm{Ph}+)$ chronic myelogenous leukemia $(\mathrm{CML})$ or acute lymphocytic leukemia (ALL) relapsed, refractory or 
intolerant of imatinib. Blood. 2006;108: 54a. Abstract 168.

29. Naito H, Kimura S, Nakaya Y, Naruoka H, Kimura S, Ito S, et al. In vivo antiproliferative effect of NS-187, a dual Bcr-Abl/Lyn tyrosine kinase inhibitor, on leukemic cells harbouring Abl kinase domain mutations. Leuk Res. 2006;30:1443-6.

30. Yokota A, Kimura S, Masuda S, Ashihara E, Kuroda J, Sato K, et al. INNO 406, a novel BCR-ABL/Lyn dual tyrosine kinase inhibitor, suppresses the growth of $\mathrm{Ph}+$ leukemia cells in the central nervous system, and cyclosporine A augments its in vivo activity. Blood. 2007;109:306-14

31. Giles FJ, Cortes JE, Jones D, Bergstrom DA, Kantarjian HM, Freedman SJ. MK-0457, a novel kinase inhibitor, is active in patients with chronic myeloid leukemia or acute lymphocytic leukemia with the T315I BCR-ABL mutation. Blood. 2007;109: 500-02.

32. Carmena M, Earnshaw WC. The cellular geography of aurora kinases. Nature Rev Mol Cell Biol. 2003;4:842-54.

33. Carter TA, Wodicka LM, Shah NP, Velasco AM, Fabian MA, Treiber DK, et al. Inhibition of drug-resistant mutants of ABL, KIT, and EGF receptor kinases. Proc. Natl Acad. Sci. USA. 2005; 102:11011-16.

34. Shah, NP, Skaggs B, Branford S, Hughes TP, Nicoll JM, Paquette $\mathrm{RL}$, et al. The most common dasatinib-resistant BCR-ABL kinase domain mutations in patients with chronic myeloid leukemia are sensitive to VX 680: rationale for early combination kinase inhibitor therapy. Blood 2006;108, Abstract 2175.

35. Young MA, Shah NP, Chao LH, Seeliger M, Milanov ZV, Biggs WH 3rd et al. Structure of the kinase domain of an imatinibresistant $\mathrm{Abl}$ mutant in complex with the Aurora kinase inhibitor VX 680. Cancer Res.2006;66:1007-14.

36. Giles FJ, Cortes JE, Jones D, Bergstrom DA, Kantarjian HM, Freedman SJ. MK-0457, a novel kinase inhibitor, is active in patients with chronic myeloid leukemia or acute lymphocytic leukemia with the T315I BCR-ABL mutation. Blood. 2007;109: 500-02.
37. Adrián FJ, Ding Q, Sim T, Velentza A, Sloan C, Liu Y, et al. Allosteric inhibitors of BCR-ABL dependent cell proliferation. Nature Chem Biol. 2006;2:95-102.

38. Gumireddy K, Baker SJ, Cosenza SC, John P, Kang AD, Robell KA, et al. A non ATP competitive inhibitor of BCR-ABL overrides imatinib resistance. Proc. Natl Acad. Sci. USA. 2005;102:1992-7.

39. Giles F, Fischer T, Cortes J, Garcia-Manero G, Beck J, Ravandi F, et al. A phase I study of intravenous LBH589, a novel cinnamic hydroxamic acid analogue histone deacetylase inhibitor, in patients with refractory hematologic malignancies. Clin Cancer Res. 2006; 12:4628-35

40. Fiskus W, Pranpat M, Bali P, Balasis M, Kumaraswamy S, Boyapalle $\mathrm{S}$, et al. Combined effects of novel tyrosine kinase inhibitor AMN107 and histone deacetylase inhibitor LBH589 against Bcr-Abl-expressing human leukemia cells. Blood. 2006;108:645-52.

O tema apresentado constou do programa do Encontro AIBE. Avaliadores: Professores Ângelo Maiolino, Cármino Antonio de Souza e Marcio Nucci.

Publicado após concordância do editor.

Conflito de interesse: não declarado.

Recebido: 06/05/2008

Aceito: 08/05/2008 